\title{
Hanno Milesi, Robert Schmidhammer (eds.): How to Improve the Results of Peripheral Nerve Surgery
}

\author{
Acta Neurochirurgica Supplementum, 100, 2007, IX, 185 pp. Hardcover $€$ 197,95 \\ Springer, Wien, New York, ISBN 13:978-3-211-72955-7
}

Pierre Kehr · Alain Graftiaux

Received: 26 October 2008/Accepted: 27 October 2008/Published online: 15 November 2008

(C) Springer-Verlag 2008

This book corresponds to a compilation of articles of acta neurochirurgica.

The great majority of the articles are results of experiments.

This book is divided into several parts: the first relates to the surgery of the nerves with many articles on the possibilities of Clerc's Offices and implants and the utility of the lateral coaptations. The second relates to cerebral plasticity in post-surgical recovery of the nerves. The third relates to compressions and irritations in particular in the thoracic outlet syndrome. The last relates to the muscles in the nervous surgery.

It will interest all the surgeons being interested in the surgery of the nerves, and which will find there joined together by pole of interest, what to satisfy their curiosity on last the development of research on nervous repair.

Conflict of interest statement No funds were received in support of this study.

P. Kehr $(\bowtie) \cdot$ A. Graftiaux 